\title{
Evaluating the impacts of food systems
}

\author{
Book review by Charles Francis ${ }^{a}{ }^{*}$ and Amy Swoboda ${ }^{b}$ \\ University of Nebraska-Lincoln
}

\section{Review of A Framework for Assessing Effects of the Food System, by Institute of Medicine \& National Research Council. (2015). Published by The National Academies Press, Washington, D.C. http://dx.doi.org/10.17226/18846. Available as paperback or free PDF; 430 pages. Publisher's website: http://www.nap.edu/catalog/18846/a-framework-for-assessing- effects-of-the-food-system}

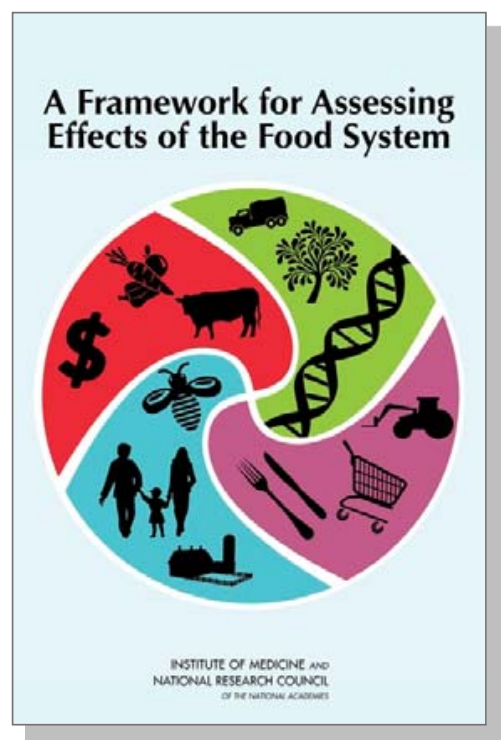

Submitted December 11, 2015 / Published online January 26, 2016

Citation: Francis, C., \& Swoboda, A. (2016). Evaluating the impacts of food systems [Book review]. Journal of Agriculture, Food Systems, and Community Development, 6(2), 307-310. http://dx.doi.org/10.5304/jafscd.2016.062.005

Copyright (C) 2016 by New Leaf Associates, Inc.

B ringing order and clarity to the analysis and evaluation of food systems is an elusive goal, especially when multiple agencies are involved in the design and implementation of policy. Many

a * Corresponding author: Charles Francis, Department of Agronomy \& Horticulture; 279 Plant Science Building, University of Nebraska-Lincoln; Lincoln, Nebraska 685830915 USA; cfrancis2@unl.edu

b Amy Swoboda, Department of Agronomy \& Horticulture, University of Nebraska-Lincoln; swoboda.amy@gmail.com

Charles Francis teaches agroecology, organic farming, and land use courses in the Department of Agronomy and Horticulture at UNL. His research is on long-term rotations, resourceefficient croppng systems, and local food systems alternatives.

Amy Swoboda has expertise in water and other natural resource law, and assists in teaching courses about urban sprawl and land grabs in the Global South. She has conducted research in Egypt on water law and long-term planning. actors in the system are involved, from input suppliers to farmers, from companies in processing to wholesale and retail sales, and to those concerned with nutrition and health. The mix of public and private organizations further complicates communication, and universities are little help with their "silo" organizational structure into specialized departments. A Framework for Assessing Effects of the Food System provides a comprehensive study of how we could assess our food system, plus some useful recommendations for improvement.

After an overview of the U.S. food system, there are chapters on health, the environment, social and economic issues, and an integrative look at this "complex adaptive system" and why it is so difficult to study. The report concludes with details on the analytic framework it used, six case studies, and conclusions. There are useful appendices with the meeting agendas, tables of data, and 
biographies of the members of the committee, who essentially should be considered the co-authors of this book. In this review we examine each section briefly and then conclude with an evaluation of the conclusions and suggestions for further exploration that were not considered in the report.

In addition to the thoroughness typical of studies by the National Academies, this food system review provides valuable insights on how to deal with complex systems. Noteworthy among them are emphases on systems and holistic thinking, principles of ecology and agroecology such as hierarchical organization of subsystems, and potentials of integration efficiencies found in complementary activities among groups that often do not communicate with each other. The six food system case studies may not be the most frequently cited examples expected by some readers. Yet they are exemplary in spanning issues from antibiotic use and animal welfare to nutrient management alternatives in crop production, and from consumption patterns and human health to the future importance of biofuels for energy independence. This wide spectrum of examples provides appeal to a broad audience, and each example illustrates the complexity of designing a resource-efficient and healthy food system and society. Our review adds value by examining strengths and weaknesses of the report.

In both the summary and the introduction, the analytical framework is spelled out in detail. A committee composed of experts collected an exhaustive volume of information and met five times to assess its resource base. The committee then held public sessions and a lengthy workshop. The committee members developed a consensus on definitions and uncovered the myriad complexities of interactions that complicate a simple understanding of this country's food system. They set boundaries around the U.S. food system for the purpose of analysis, accepting that this is difficult given the large degree of participation by international manufacturing and trade corporations in the global food market. They consciously avoided the public policy arena while recognizing the danger of analyzing strengths and weaknesses of the system without exploring the effects of policy on its functions and decisions by key food system players.

"Food supply chain" is found as a descriptor in most definitions of the food system, so it is not surprising that this was chosen as the conceptual model to organize this framework for analysis. The linear, cause-and-effect model simplifies the analysis, and as presented in text and figures includes both the steps in the chain and quantitative estimates of material flows along the chain. Those unfamiliar with the food sector may be surprised to see how little value of production (12\%) is accumulated on the farm, with food services, retail and wholesale trade, and agribusiness absorbing about $75 \%$ of the value of each food dollar spent by consumers. There is discussion about how the food system is imbedded in a larger socio-economic and biophysical context of society that involves markets and policies. Timelines provide historical perspective, and figures trace land and labor in agriculture, calories consumed and obesity, total food expenses and amount spent outside the home, all useful to gain a broad appreciation of trends in the system. A brief section on the changing impact of the food system on the environment is overshadowed by detailed descriptions of changing policies and markets, certainly key issues in describing food system function and necessary to include in any assessment of this sector. In one figure, a dashed line indicates less frequently recognized feedback from consumers to farmers. Had an ecologist served on the committee, there might have been more consideration of the food system as a web of connections rather than simply a chain. This perspective comes from agroecology, where inputs include contemporary resources on the farm, such as sunlight, rainfall, and snowfall, and not just the purchased inputs. The cycle would also reveal a system where very little material from food "waste" is recycled back into the production system; waste is a huge factor that accounts for some $30 \%$ to $40 \%$ of all food produced, enough if captured to easily satisfy global food needs for decades into the future with current production practices. There is also a lack of life-cycle analysis of the production-to-consumer flow of food, and consequently an underestimation of the energy and other resources used to produce, process, transform, and transport food through the system. Thus 
the overview and groundwork for the analysis have serious omissions that should be corrected in future searches for rigorous and comprehensive treatment of how to evaluate the food system.

The chapter on health effects of the system explores how food today affects the U.S. population and attempts to assign causes for these effects. Important to the discussion is emphasizing that food does not operate in isolation, and that many other factors, including lack of exercise, sedentary jobs, and changing dietary patterns and choices are confounded in any overall analysis of the system. Well-known consequences of poor diets such as growing incidence of obesity, diabetes, and heart disease are described and attributed to unhealthy food choices. When market forces and intense lobbying efforts by major food manufacturers and commodity groups drive some regulations and recommendations, it is unlikely that the result will be in line with healthy diets and public health goals. This quandary seems difficult to solve in a capitalist system. The chapter mentions new research revealing that individual genetic differences and cultural norms affect food choices, and noting awareness that one recommendation does not fit all. Public health programs depend on policies, education, and voluntary efforts by industry, although many question the objectivity of both research and education sponsored by those who have products to sell. There is ample data provided and useful figures to illustrate health factors such as obesity, chronic diseases and nutrient deficiencies, plus biological and chemical pollutants. Again, the chapter is rich with references and a number of suggestions on developing indicators.

Environmental effects of the food system described in the next chapter include pollution and contamination, depletion of nonrenewable resources, and disruption of other activities of society. The first pair receives the most attention in the press and is most easily measured. The text is accompanied by useful figures that trace the trends of these effects over the past two to three decades. Complexities emerge in analysis, such as the mixed effects of confined animal operations that reduce time on feed and reduce methane emissions along with the pollution from these point sources of production. Lack of monetary rewards for ecosystem services provided by agriculture confound attempts to measure and encourage improvements, but there is growing recognition of these emergent properties of food production.

Most importantly, the economic and social aspects of the food system contributing to health and well-being are multiple, interrelated, and complex. For example, equity in wealth, working conditions, and nutrition education all contribute to the overall health of the U.S. population. Related to the economic efficiency of farming, increasing productivity with reallocation of inputs demonstrates the positive effects of research and adoption of new technologies, although there are substantial concerns about economic limits of profits due to yield plateaus in major crops (maize, wheat, and soybeans). While labor inputs have decreased markedly, fertilizer and pesticide use has increased, spurring concerns about higher levels of pollution from agriculture. In terms of safety, farming is one of the most dangerous occupations in the country, so it is good to learn that over $90 \%$ of farm families do have some form of insurance, well above the national average. Farm and retail food employees have the lowest wages, and virtually all people in the food industry have salaries below the national average. Food prices have gone up more than overall inflation in the consumer price index over the past decade. All these data related to economic and social dimensions of food systems provide valuable baseline results on which to develop credible analyses and indicators.

The overall food situation in the U.S. is described as a complex adaptive system (chap. 6, p. 233), which explains the difficulty in deriving useful indicators for assessing the health of the system. There are multiple factors involved and important feedback loops that evolve over time in response to resource availability, markets, and policy. It is helpful to see this perspective, one that could inform our long-term focus on food webs and cycles rather than today's insistence on treating the system as a food chain. The system is complex and dynamic and is variable both spatially and temporally, which complicates the quest to establish a useful framework for analysis. This theme is continued in Chapter 7 with a focus on how well a framework can be used to evaluate a food system, 
how this must relate to its effects on the population, and its potential to establish a baseline for future comparison. This concluding discussion is the most integrative and holistic in the book, where recognition of the need to look at the entire food system, the multiplicity of effects and interactions, and the importance of a time dimension are all brought into focus. The challenge of objectively choosing indicators and scales, putting priority or weights on each indicator, and combining these into something workable that can inform policy and future economic decisions is clearly articulated. A reader leaves this chapter convinced that measurement is possible, but that how a procedure is designed could strongly influence the application and results. It is essential that this be done by persons without specific vested economic interests, although all the players are obviously consumers and have a stake in the outcomes.

The six case studies represent a wide range of food system-related activities and explore the diversity of possible applications. Their presentation following the same organization into subtopics allows comparison across cases; for example, increased fish consumption, along with that of fruits and vegetables, could improve diets and health compared with our present meat-rich habits. Contemporary issues of growing concern to the public include the impacts of nitrogen on the environment and animal welfare as illustrated by poultry housing. Trade-offs between the production of biofuels and food are discussed in one case, a critical current issue that often avoids the obvious alternative of reducing demand through conservation. One critique we have of the selected cases is their focus on short-term issues, a choice which overlooks creative food production and food system alternatives, such as organic farming, taking advantage of local food opportunities, shifting to grain-based diets, and purchasing more in-season products, among others. The focus seems to be on fine-tuning the current model, a realistic yet conservative approach that begs to be extended using the same metrics to futuristic alternatives. Overall, the committee concludes that having a framework for measuring impacts of the food system is a critical task to help inform our priorities and policies, while at the same time admitting that this is a huge chore that is fraught with challenges that come from limited and contradictory science, vested economic interests, and the complacency of a population that fails to see many of the faults in the current system. Readers should take seriously the observation by Pulitzer Prize winner René Dubos, who said, "Wherever human beings are concerned, trend is not destiny." 